\title{
STEM Education Internship Program
}

\section{Dr. Asad Yousuf, Savannah State University}

Asad Yousuf is the Coordinator and Professor of Electronics Engineering Technology at Savannah State University

\section{Dr. Mohamad A. Mustafa, Savannah State University}

Mohamad Mustafa is a Professor of Civil Engineering Technology and the Chair of the Engineering Technology Department at Savannah State University (SSU). He has six years of industrial experience prior to teaching at SSU. He received his BS, MS, and $\mathrm{PhD}$ in Civil Engineering from Wayne State University, Detroit, Michigan.

\section{Dr. Mir M. Hayder, Savannah State University}

Dr. Hayder is an Assistant Professor in the Department of Engineering Technology at savannah State University, GA. He received PhD in Mechanical Engineering from McGill University, Canada. His research interest lies in the areas of fluid-structure interaction, flow-induced vibrations, syngas and blended fuel combustion, and flow and structural simulations, robotics and STEM education.

\section{Mr. Alberto G. De La Cruz}

Dr. Kisha Renee Cunningham 


\title{
STEM Education Internship Program
}

\begin{abstract}
America's colleges and universities are not producing an adequate amount of K-12 school teachers, particularly secondary school teachers in the high need STEM fields of physics, chemistry, math, and computer science. This shortage have an impact on the quality of STEM education because schools have to accept teachers with less qualifications [2]. This discourages young students from pursuing careers in Science, Technology, Engineering, and Mathematics upon entering college due to limited comprehension and exposure to these subjects [4]. To address this critical need, XXX University in partnership with YYY College and the 6-12 school system designed/developed a comprehensive five week Summer Educational Internship program. This program targets rising college sophomores majoring in Science, Mathematics, and Engineering Technology to prepare them for teaching students in grades 6-12. Over a 5 week period the students are introduced to a semi-formal education on subjects such as 3D Modeling, Programming, and Robotics. This program also involves high aptitude rising college juniors as student instructors to mentor students as part of an advanced group called Upward Bound. These juniors are advised by a lead instructor to create their lessons and apply them in the classroom. This summer program aims to provide in-class teaching experience to sophomore and junior college students majoring in STEM fields, in the hopes that these students will develop an interest in pursuing a future as a STEM educator. During the five week teaching period, fifteen students (12 from XXX and 3 from YYY) receive a stipend of $\$ 1,000$ to participate in the summer internship program and work with a professor to prepare and implement their lessons. This paper reports on student teaching, observations, and hands on activities associated with the Upward Bound/UNITE, and Noyce programs.
\end{abstract}

\section{Introduction}

Elementary and secondary student enrollment in the united states has increased steadily since the 1980s. During this time high school graduation course requirements increased in core academic subjects, especially math and science, where course enrollment grew by $69 \%$, and $60 \%$ respectively. This growth has not been met with an increased supply of qualified teachers, in fact during this time teacher retirement grew by $141 \%$. Due to this disparity, there is a major increase in the demand for qualified STEM teachers. In surveys of school districts, position openings in physics, chemistry, and math are commonly the hardest to fill with qualified personnel [1]. This disparity has led to a large percentage of STEM teachers with no college major or minor in their main subjects, or they have no complete certification. Among math teachers, $40 \%$ fall into this description, while over $60 \%$ of physics, chemistry, and earth science teachers do so[2]. 
This concern over STEM shortages is justified as STEM jobs are projected to grow by $13 \%$ from 2012 - 2022 which is an increase of about 1 million jobs over a 10 year period. Only $5 \%$ of United States workers are employed in STEM jobs, but these jobs drive 50\% of the United States' economic growth. To put this in perspective, for each new software, technology, or life sciences job created, five additional jobs are created [3].

Of these new STEM jobs, 92\% will require post-secondary education of some kind. Research has shown that success in post-secondary education in STEM fields is highly correlated with specialization in elementary and secondary school, which is driven by qualified teachers. Studies indicate that current standards are inadequate as can be seen in the poor quality of many current STEM educators and student outcomes. Despite the United States offering more than 1200 teacher education programs at Universities and 130 alternate licensing routes, this lack of a predominant standard has led to an uncoordinated preparation of STEM teachers and a lack of preparedness among new educators [4].

To address the problems in STEM education and to increase the supply of qualified teachers, XXX University and YYY technical college worked in tandem to produce an Educational Internship program funded by the NSF-Robert Noyce Scholarship and UNITE program. This program was designed to meet the demands of STEM teachers in the Savannah Chatham County Public school system. Specific elements of the program include the following:

1. Launching an aggressive recruitment plan for talented math and engineering majors to pursue teaching careers in 6-12 secondary schools;

2. Implementing a comprehensive STEM teacher training program;

3. Providing Summer Educational Internship Program (SEIP) to rising sophomores;

4. Providing Field Observation Experiences for sophomores;

5. Providing $\$ 10,000$ scholarships to talented math and engineering juniors and seniors to pursue a teaching career by acquiring education training through SSU teacher education math, civil, and electronics engineering technology programs;

6. Providing \$10,000 stipends for STEM professionals or recent STEM graduates to become teachers;

7. Enhancing the local district's teacher mentoring and professional development program to improve teacher performance and retention

This paper will describe the five week Summer Education Internship program designed to introduce high quality students to the teaching profession and to promote an interest in teaching.

The main goal for the Noyce Summer Internships are to encourage retention and broaden student exposure to STEM education. Selected interns are sophomores and juniors pursuing STEM disciplines. This grant allows the SSU/STC Summer Education Internship Program to oversee internships in STEM-focused, K-12 summer educational programs in order to provide SSU/STC students a chance to observe and engage in informal STEM education opportunities within the community. 
Noyce SEIP students were assigned to the Upward Bound/UNITE Summer Program.

Students selected for this program developed an understanding of various engineering and technology programs and how these programs relate to the work environment.

The course emphasized hands-on activities in Robotics Technology and Design/Modeling
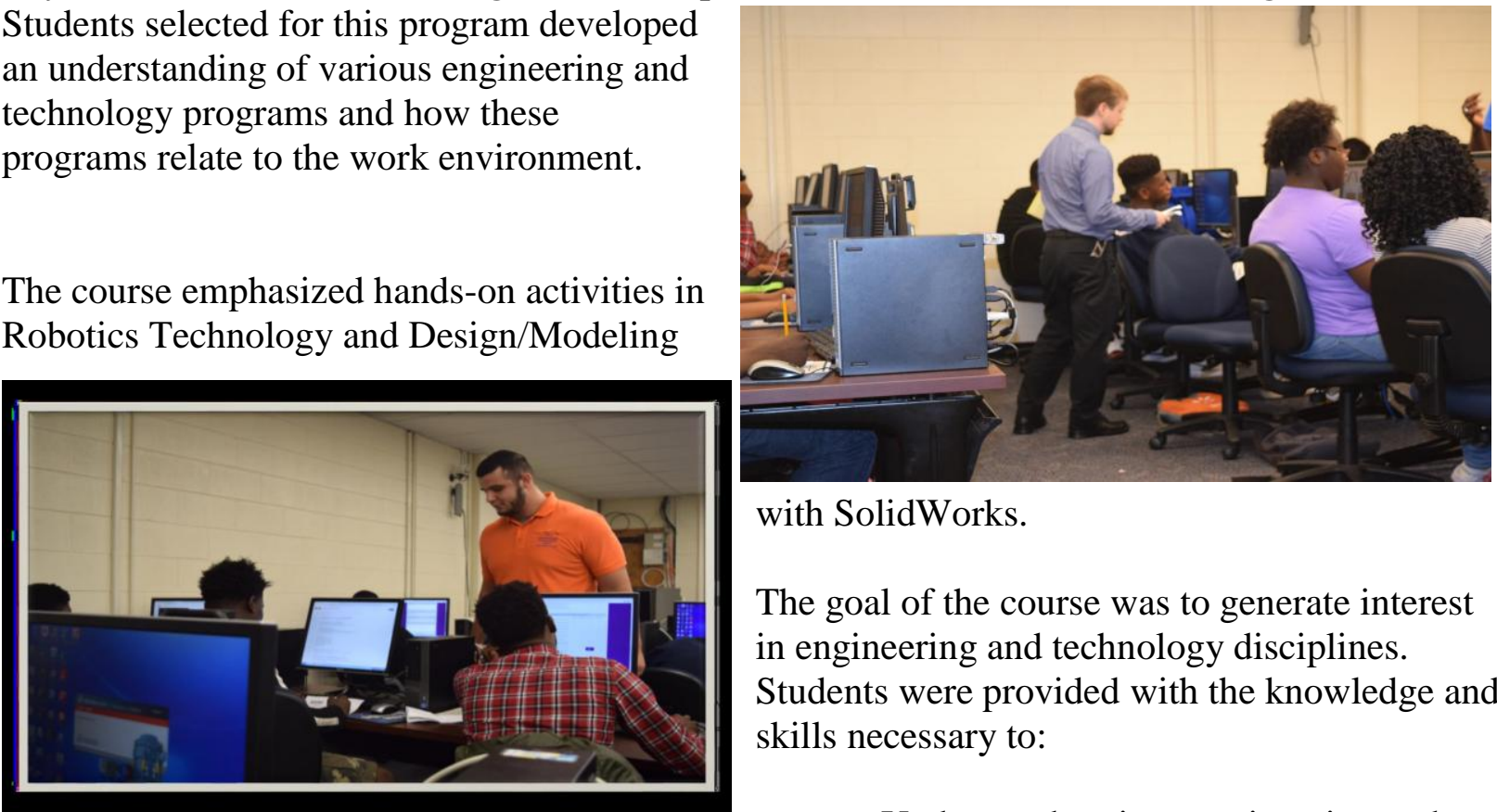

with SolidWorks.

The goal of the course was to generate interest in engineering and technology disciplines.

Students were provided with the knowledge and skills necessary to:

- Understand various engineering and technology disciplines

- Work with the Robotics Technology/SolidWorks

- Participate in Robotics and SolidWorks team competition
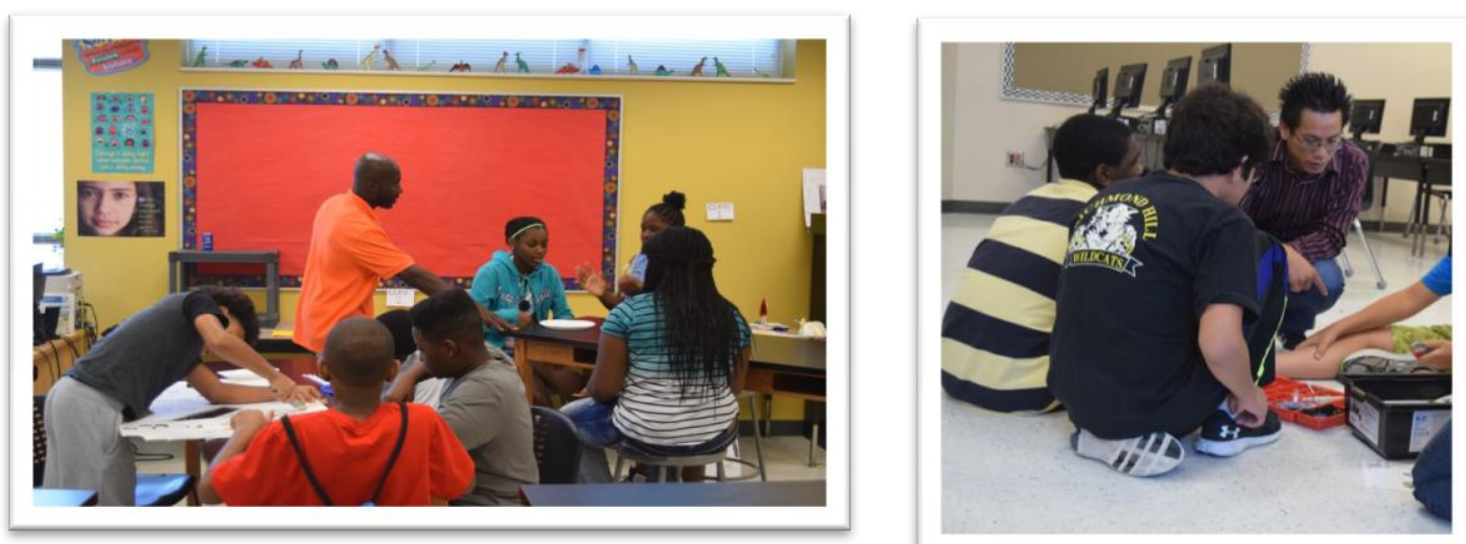

\section{Activities}

During the 5-week long summer program, students were introduced to robotics technology and 3D modelling. There were three distinct units that encompassed the five

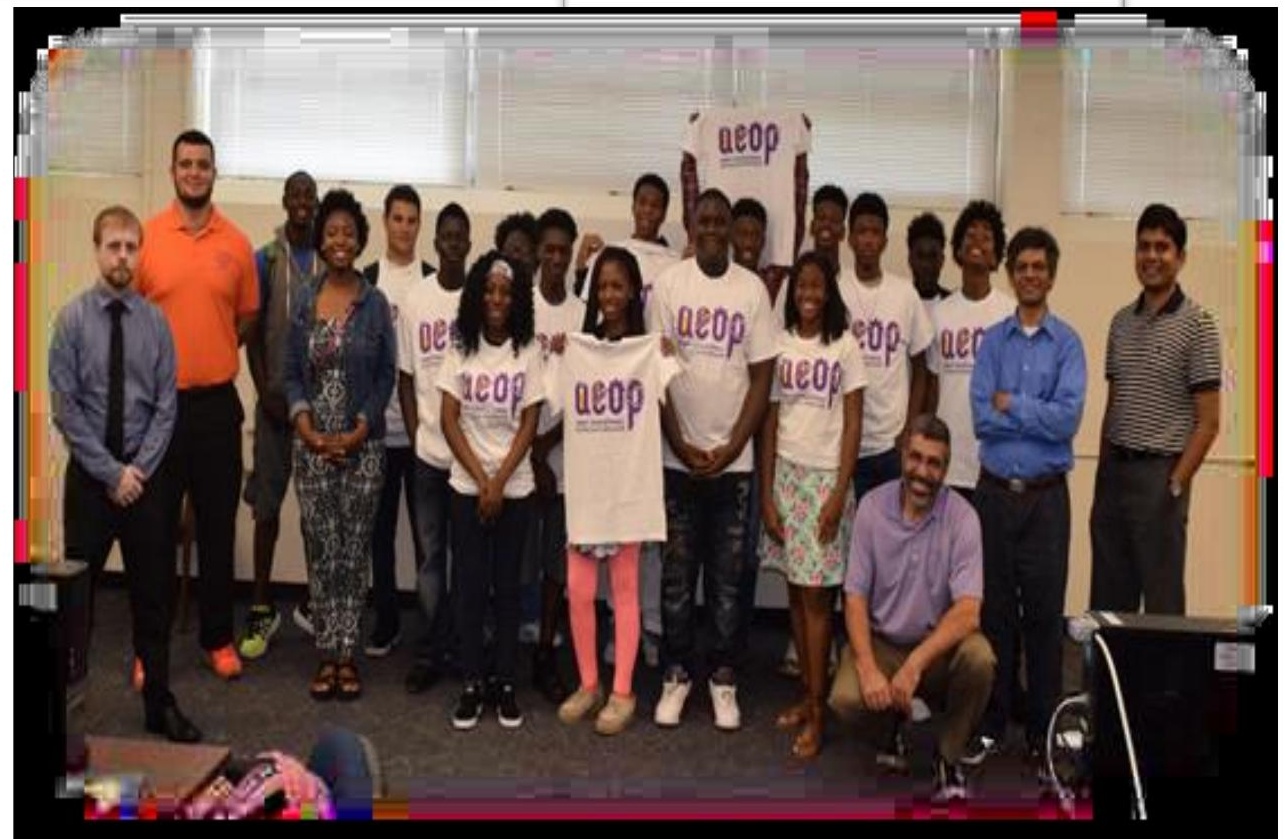


week period; the first two weeks focused on robotics technology, the second two on 3D modeling, and the fifth week involved a competition that included both instructional units. This breakdown is shown in Table 1. Both a civil and an electronics engineering technology student were selected to work under the mentoring and supervision of two faculty members. Each had the responsibility to introduce the topics of study to the high school students in an interactive classroom environment. Faculty members were present in the classroom to mentor the student instructors. Throughout the program, the two college students switched roles to better interact with the high school students, making sure that each topic and activity was fully understood.

Table 1: Instructional Units/Modules

\begin{tabular}{|c|c|}
\hline UNITS & Time \\
\hline \multicolumn{2}{|l|}{ WEEKS 1 \& 2} \\
\hline Studying Engineering: A road map to a rewarding career & 1.0 Hour \\
\hline $\begin{array}{l}\text { Robotics Technology: } \\
\text { - Introduction to Robotics } \\
\text { - Building your Activity Bot } \\
\text { - Introduction to Microcontroller and C programming } \\
\text { - Applications of sensors in robotics } \\
\text { - Navigation of Activity Bot } \\
\text { - For Robotics Technology see the schedule Map below }\end{array}$ & 8.0 Hours \\
\hline \multicolumn{2}{|l|}{ WEEKS 3 \& 4} \\
\hline $\begin{array}{l}\text { 3D Modeling Structures } \\
\text { - Computer Aided Design Basics } \\
\text { - Basic Part Modeling with SolidWorks } \\
\text { - Basic Assembly Modeling with SolidWorks } \\
\text { - Basic Drawing (Multiview) with SolidWorks } \\
\text { - Basic Simulations with SolidWorks } \\
\text { - Applications of Design and Modeling in structures }\end{array}$ & 8.0 Hours \\
\hline \multicolumn{2}{|l|}{ WEEK 5} \\
\hline $\begin{array}{l}\text { Robotics and 3D Modeling Competition } \\
\qquad \quad \text { Team Projects }\end{array}$ & 3.0 Hours \\
\hline
\end{tabular}

The goal of the robotics technology activities was to demonstrate how to effectively operate the mobility functions of the Activity bot. This was done by using the Parallax ActivityBot to introduce key robotics concepts and basic microcontrollers operation and programming. The ActivityBot kit was used for all the activities as it had different sensors and components that could all be easily interfaced with the microcontroller [5]. In order to utilize the ActivityBot, an introduction to C Programming and the IDE (Integrated Development Environment) was given to the students [6]. Table 2 shows the detail-mapped schedule for the daily robotics technology activities. 
Table 2: Mapped Schedule-Robotics Technology

\begin{tabular}{|c|c|c|c|c|c|}
\hline & Monday & Tuesday & Wednesday & Thursday & Friday \\
\hline Week 1 & ------- & $\begin{array}{c}\text { Introduction } \\
\text { to Robotics 1: } \\
\text { What is a } \\
\text { Robot? }\end{array}$ & $\begin{array}{l}\text { Introduction } \\
\text { to Robotics 2: } \\
\text { Building your } \\
\text { ActivityBot }\end{array}$ & $\begin{array}{c}\text { Introduction to } \\
\text { Microcontrollers: } \\
\text { How a } \\
\text { Microcontroller } \\
\text { Works }\end{array}$ & $\begin{array}{c}\text { Introduction } \\
\text { to } \\
\text { Programming: } \\
\text { Running your } \\
\text { first C } \\
\text { Programs }\end{array}$ \\
\hline Week 2 & $\begin{array}{c}\text { Activity 1: } \\
\text { Testing the } \\
\text { ActivityBot's } \\
\text { Devices }\end{array}$ & $\begin{array}{l}\text { Activity 2: } \\
\text { Making the } \\
\text { ActivityBot } \\
\text { Travel } \\
\text { Forward }\end{array}$ & $\begin{array}{c}\text { Activity 3: } \\
\text { ActivityBot } \\
\text { Navigation by } \\
\text { Sound - } \\
\text { PING))) }\end{array}$ & $\begin{array}{l}\text { Activity 4: } \\
\text { ActivityBot } \\
\text { Geometry } \\
\text { Navigation }\end{array}$ & $\begin{array}{c}\text { Activity 5: } \\
\text { Navigation by } \\
\text { Light w/ Error } \\
\text { Beep. }\end{array}$ \\
\hline
\end{tabular}

In order to introduce the participants to the steps of creating a 3D model for analysis and testing through a computer aided software package, the students were given a discussion on the basics of $\mathrm{CAD}$ and 3D modeling, then given activities in which they created parts, assembly models, multi-view drawings, and pre- and post-processing of a simple structural simulation in SolidWorks. The detail mapped schedule for 3D modelling activities is shown in Table 3.

Table 3: Mapped Schedule-3D Modeling

\begin{tabular}{|c|c|c|c|c|c|}
\hline & Monday & Tuesday & Wednesday & Thursday & Friday \\
\hline Week 3 & $\begin{array}{c}\text { Basics of } \\
\text { CAD and 3D } \\
\text { modeling and } \\
\text { intro to } \\
\text { SolidWorks }\end{array}$ & $\begin{array}{l}\text { Creation of } \\
\text { part models in } \\
\text { SolidWorks }\end{array}$ & $\begin{array}{l}\text { Continuation } \\
\text { of creation of } \\
\text { part models } \\
\text { in } \\
\text { SolidWorks }\end{array}$ & $\begin{array}{l}\text { Creation of } \\
\text { assembly } \\
\text { models in } \\
\text { SolidWorks }\end{array}$ & $\begin{array}{l}\text { Continuation } \\
\text { of creation of } \\
\text { assembly } \\
\text { models in } \\
\text { SolidWorks }\end{array}$ \\
\hline Week 4 & $\begin{array}{l}\text { How to create } \\
\text { a multi-view } \\
\text { drawing in } \\
\text { SolidWorks? }\end{array}$ & $\begin{array}{l}\text { How to } \\
\text { prepare and } \\
\text { post-process } \\
\text { structural } \\
\text { simulation in } \\
\text { SolidWorks? }\end{array}$ & $\begin{array}{l}\text { Application: } \\
\text { Preparation } \\
\text { of a solid } \\
\text { model for } \\
\text { SolidWorks } \\
\text { Simulation }\end{array}$ & $\begin{array}{l}\text { Application: } \\
\text { Post- } \\
\text { processing } \\
\text { the result for } \\
\text { the truss } \\
\text { model }\end{array}$ & $\begin{array}{c}\text { Activity: } \\
\text { Simulation and } \\
\text { post- } \\
\text { processing of } \\
\text { results } \\
\text { conducted by } \\
\text { students }\end{array}$ \\
\hline
\end{tabular}


Figure 1 shows the assembly model that the students developed using SolidWorks [7] in the classroom. Part (a) of the figure represents the actual model and the part (b) represents an exploded view of the same model for a better understanding.

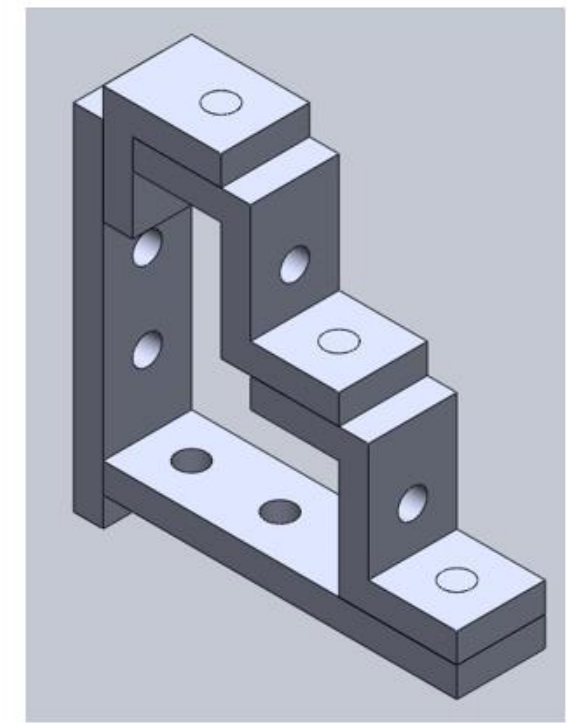

(a) Isometric assembly

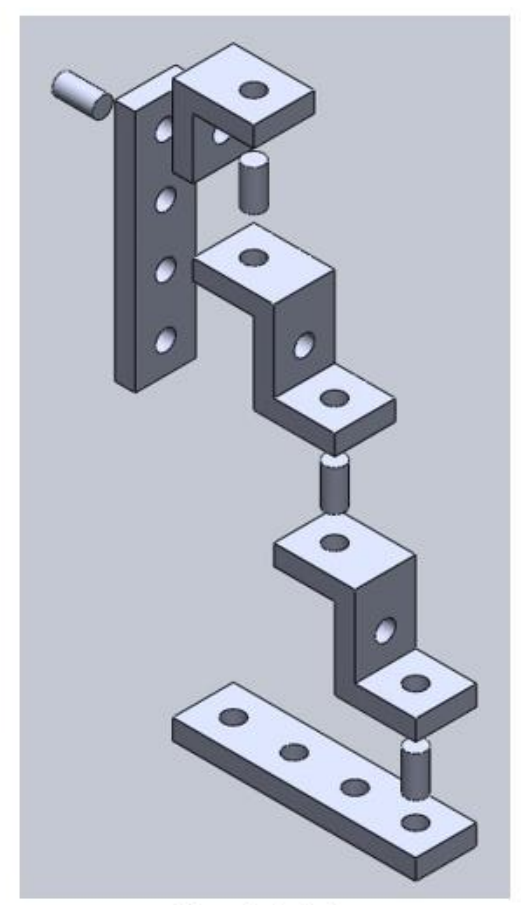

(b) Exploded view

Figure 1: Assembly model developed by students using SolidWorks

To develop the assembly model, students needed to create 4 different part files: (1) spacer, (2) Zbracket, (3) L-bracket, and (4) peg. The dimensions of the 4 part files are shown in Figures 2-5.

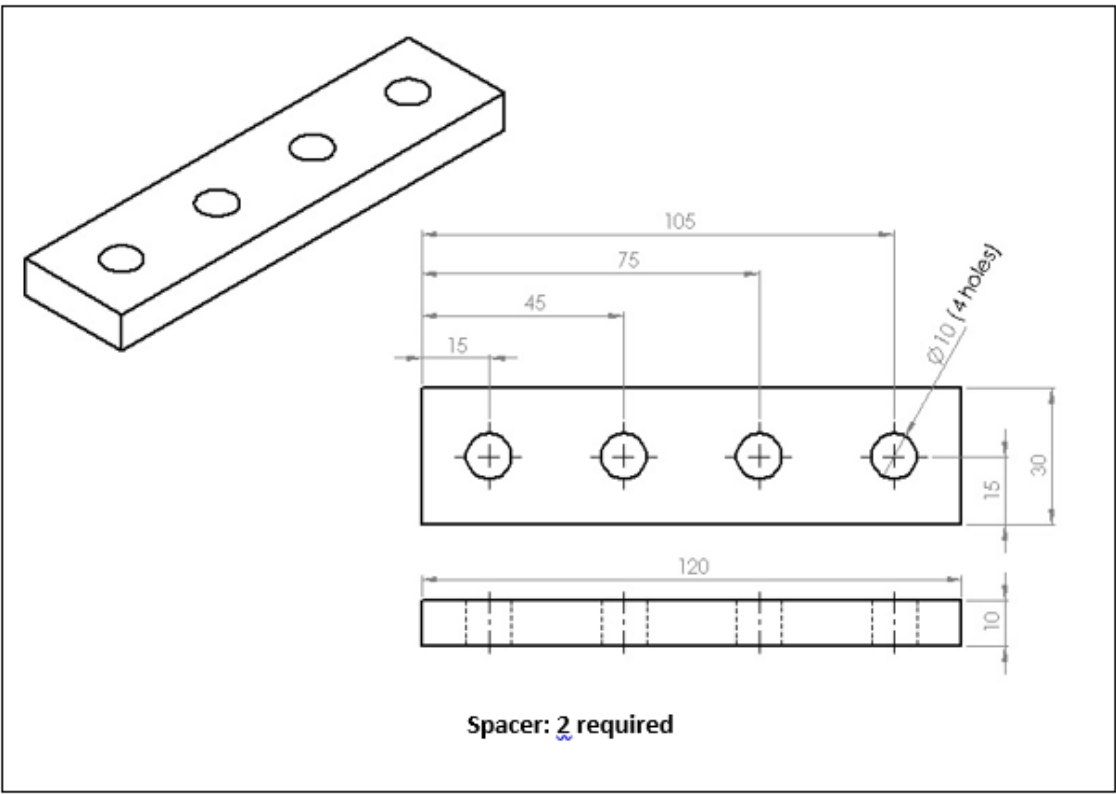

Figure 2: Dimensions of the Spacer 


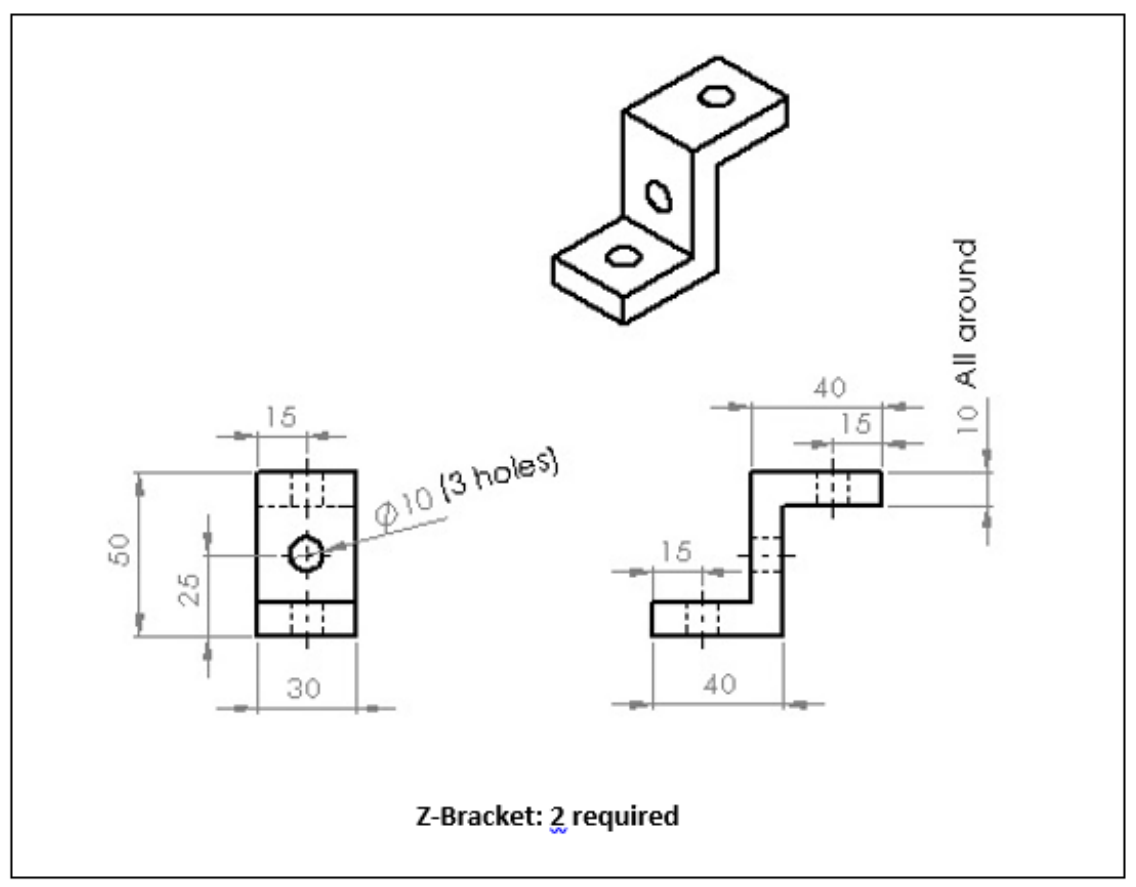

Figure 3: Dimensions of the Z-bracket

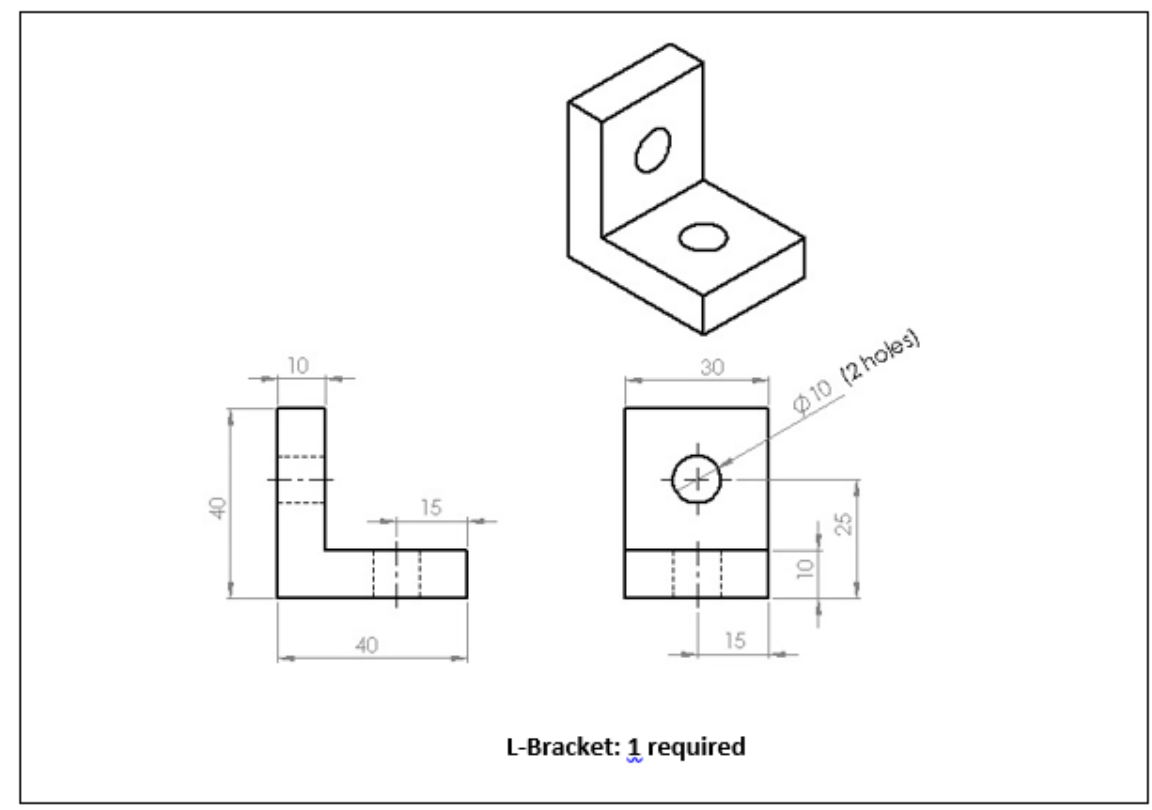

Figure 4: Dimensions of the L-bracket 


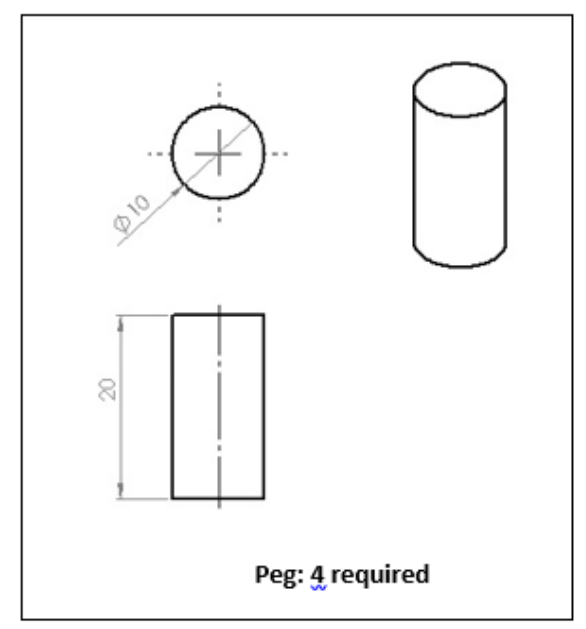

Figure 5: Dimensions of the peg

All dimensions in Figure 2-5 are in mm. Based on the dimensions shown in Figures 2-5, students developed the parts files in SolidWorks and combined them in a assembly file shown in Figure 1. As seen in Figure 1, 2 spacers, 2 Z-brackets, 1 L-bracket, and 4 pegs were required to complete the model. Students were given detailed steps for each stage of the task. The parts files were then used to demonstrate the multi-view drawing in SolidWorks.

Figure 6 shows the first activity, students were introduced to the ActivityBot microcontroller and how to use SimpleIDE which is the interface to program the microcontroller. The main objective of this exercise was for the students to become familiar with $\mathrm{C}$ language syntax [8] . 


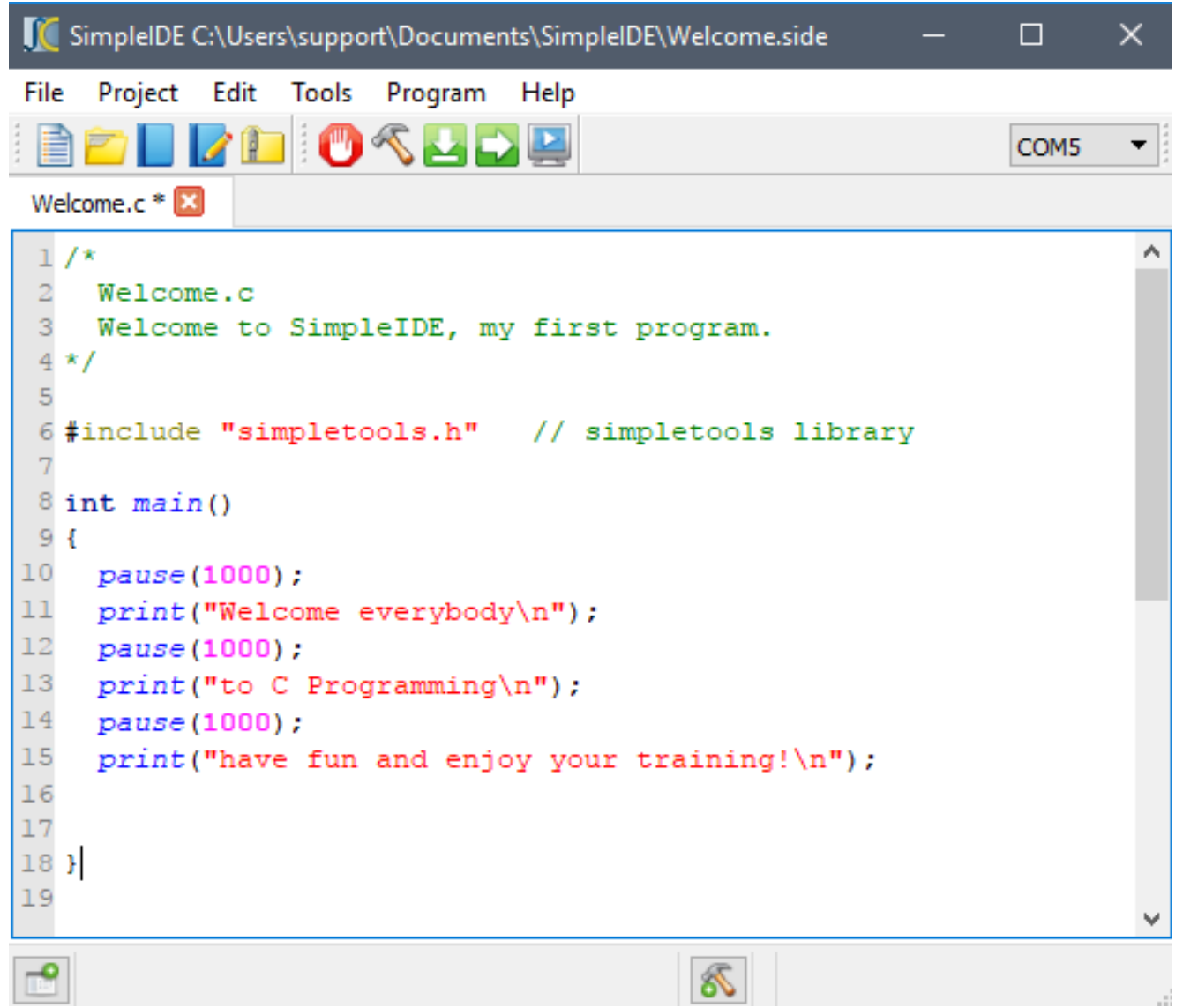

Figure 6: First program

Figures 7, 8, 9 and 10 show the activities in which students interfaced the microcontroller with an ultrasonic PING sensor to measure distance. The main objective of this exercise was for the students to understand on how the PING sensor library makes conversions by converting the echo return time to obtain the distance in centimeters or inches. In addition, students implemented and performed modifications to an existing exercise to follow objects.

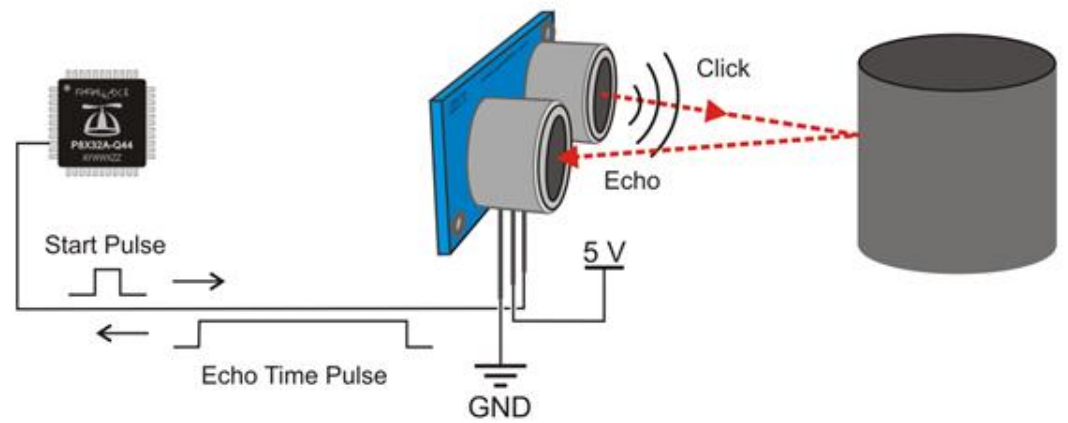

Figure 7: PING sensor - how it works 

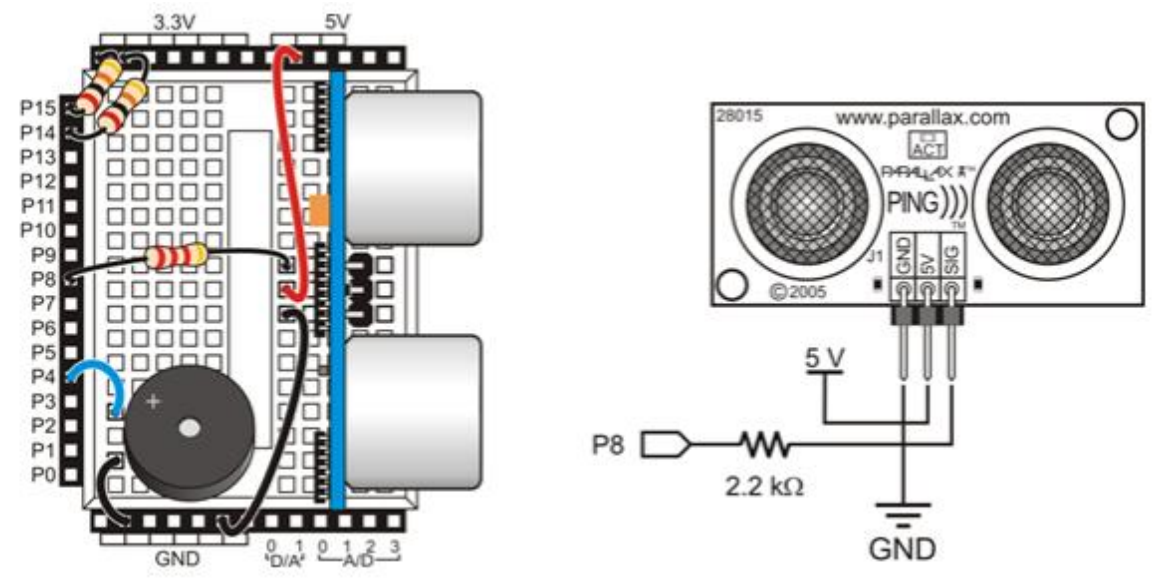

Figure 8: PING sensor pin assignment

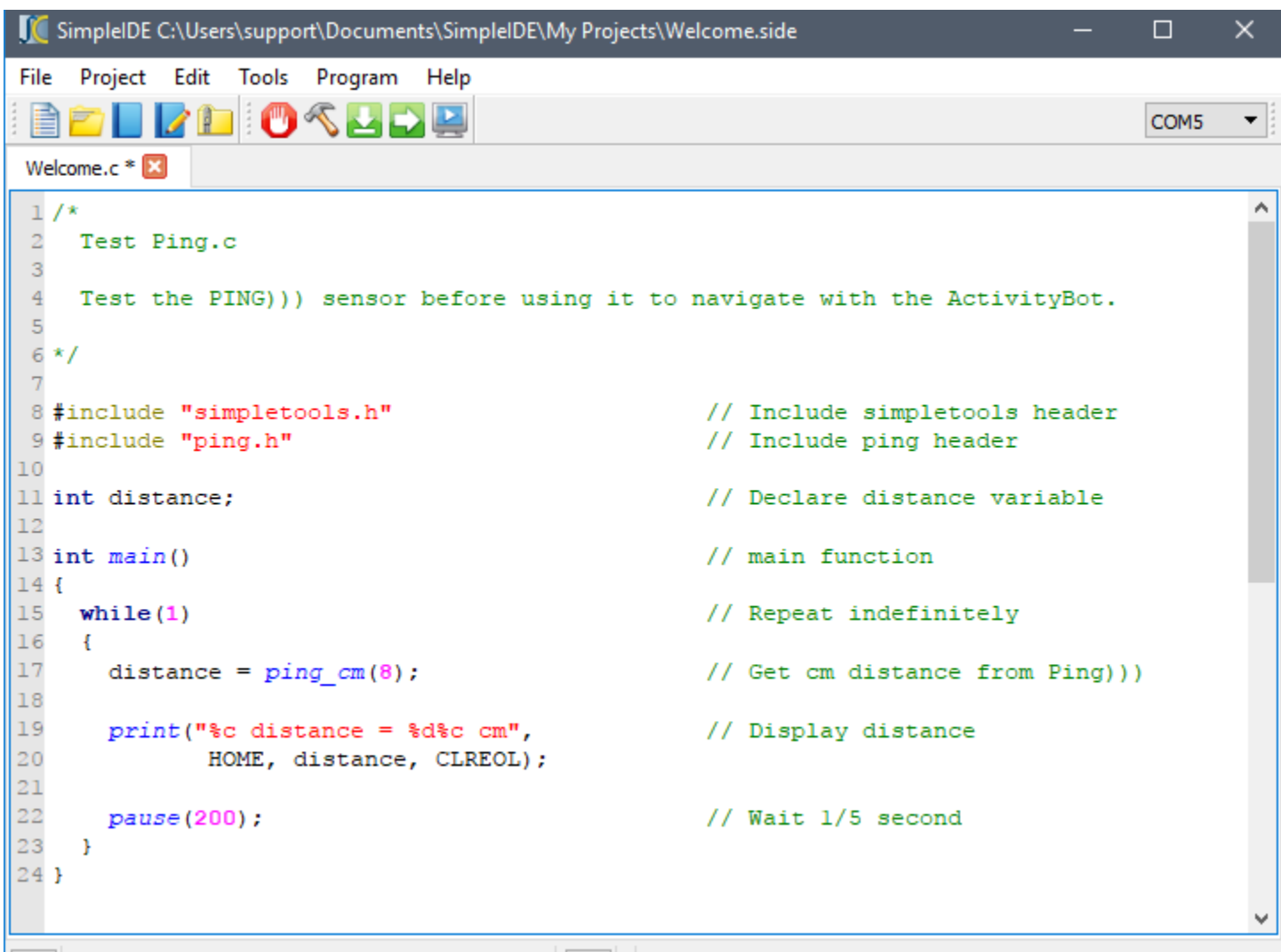

Figure 9: PING sensor exercise to determine the distance in centimeter - SimpleIDE 


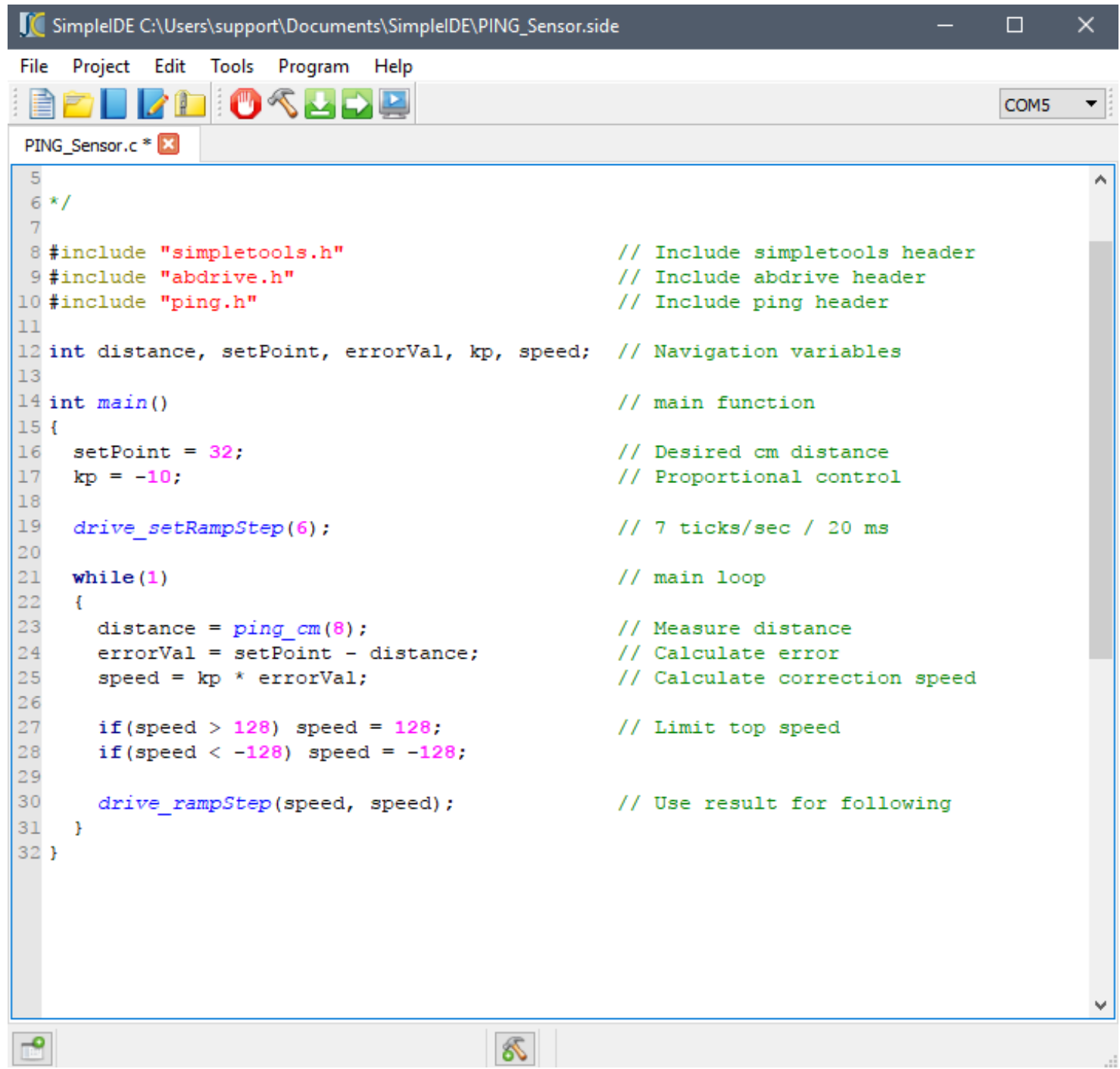

Figure 10: PING sensor - Follow the object - SimpleIDE (C syntax)

Figures 11 and 12 show the final activity (competition between groups) that students completed during the 2-week activity. The goal of the activity was for the ActivityBot to navigate around a defined racetrack, the most important parameter for this activity was for the rover to navigate the racetrack without driving over the blue lines. In previous activities students were introduced to using motors and servos to move the rover forward, backward, left and right. In addition, to complete this activity students needed to take into consideration the following parameters:

Racetrack length $=6 \mathrm{ft}$.

Racetrack width $=4 \mathrm{ft}$.

1 tick $=3.25 \mathrm{~mm}$

1 meter $\approx 3.28$ feet

1 revolution $=64$ ticks $=208 \mathrm{~mm}$

A-Bot turning radius $\approx 105.8 \mathrm{~mm}$ 


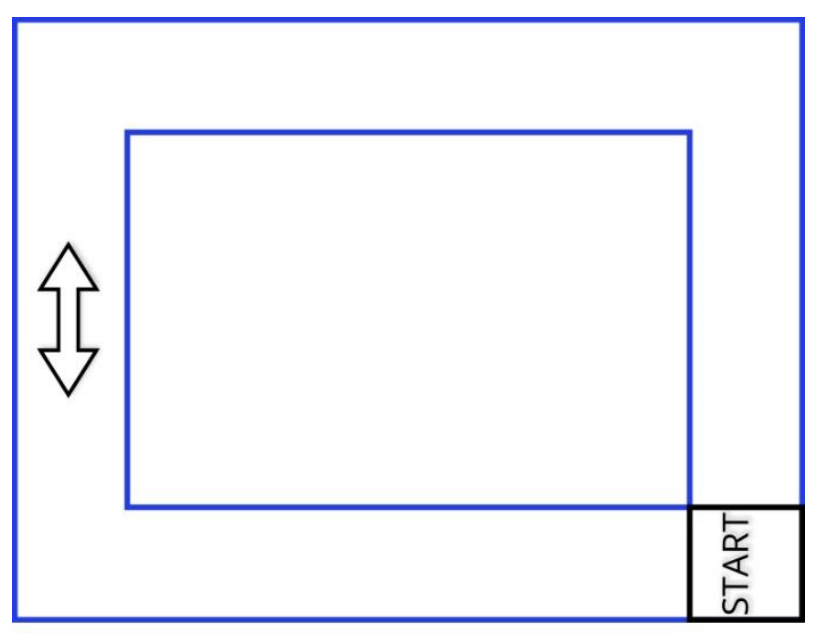

Figure 11: Racetrack

Each students' group had the opportunity to test their activity multiple times, First Place in this competition was the group that was able to complete the racetrack in less time while not driving over the blue lines.

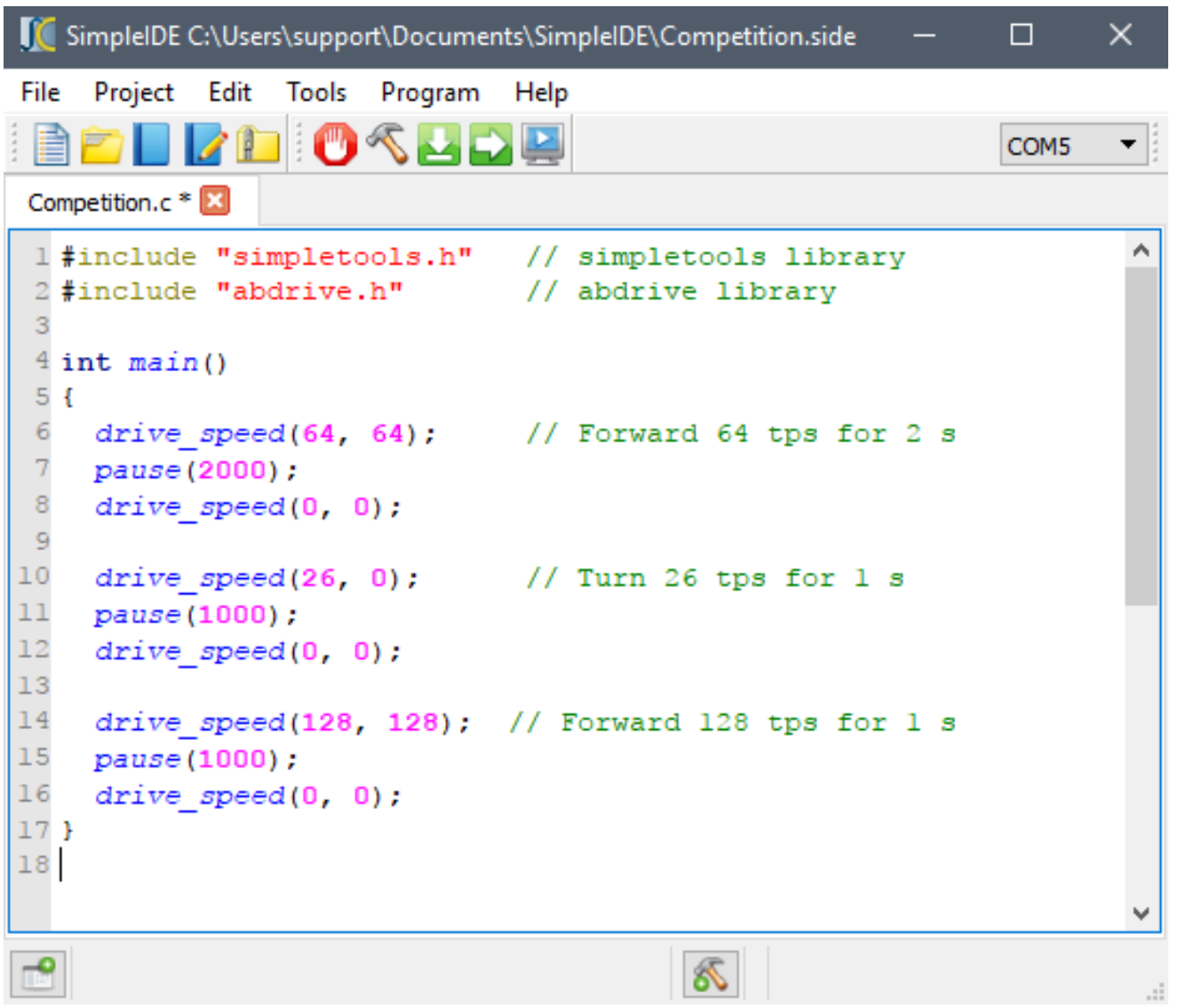

Figure 12: Sample code of initial activity. 


\section{Conclusion}

Both students (6-12) and interns participating in the NOYCE program expressed a new level of interest in the STEM field. All interns expressed a desire to enter into the teaching field during and after the program. The students graded all of the interns with high scores thus affirming the effectiveness of the teaching preparation period. The students also expressed an interest in having careers in the STEM field after receiving instruction.

These results prove that the NOYCE Summer Program met and even exceeded its objectives to introduce rising sophomores and juniors studying STEM subjects to the teaching field and successfully winning the interest of students due to effective preparation by the teaching supervisors.

References:

[1] Ingersoll, Richard.M. "Do We Produce Enough Mathematics and Science Teachers?" Kappanmagazine. (2011, March). www.gse.upenn.edu. 25 Jan. 2018.

[2] Patte, Barth. Naomi, Dillon. Jim, Hull. Breanna, Higgins. Fixing The Holes In The Teacher Pipeline: An Overview of Teacher Shortages. Center for Public Education. 2016.

[3] Public Impact. (2014). Reaching all students with excellent STEM teachers: Education leaders' brief. Chapel Hill, NC: Author. Retrieved from http://opportunityculture.org/wpcontent/uploads/2014/10/Reaching_All_Students_with_Excellent_STEM_Teachers_Education_ Leaders_Brief-Public_Impact.pdf

[4] Wilson, S. M. (2011). Effective STEM teacher preparation, induction, and professional development. Paper presented at the National Research Council's Workshop on Successful STEM Education in K-12 Schools, Washington, DC, May 10-12, 2011.

[5] What's a Microcontroller? ; Andy Lindsay, Parallax Inc.

[6] Robotics with the Boe-Bot; Andy Lindsey, ISBN 9781928982531; Parallax Inc.

[7] Engineering Design with SOLIDWORKS 2016 and Video Instruction; David Planchard; SDC publications.

[8] Expert C programming Deep C Secrets; Peter Van der Linden, ISBN 0131774298. 